\title{
A reescrita do mito das amazonas na obra \\ A Cidade das Damas de Christine de Pizan
}

\author{
Luciana Eleonora de F. C. Deplagne* \\ Universidade Federal da Paraíba
}

\begin{abstract}
Resumo: $\mathrm{O}$ presente artigo busca analisar a reapropriação do mito das Amazonas pela escritora Christine de Pizan (1364-1430), na obra A Cidade das Damas (1405), identificando na sua escrita, traços pioneiros do pensamento feminista. Para a realização do trabalho analítico, será estabelecido um diálogo entre as biografias femininas propostas pela autora em $A$ Cidade das Damas, e aquelas apresentadas pelo escritor italiano Boccaccio (1313-1375), em De Claris Mulieribus, focalizando nas duas obras a representação do mito das Amazonas.
\end{abstract}

Palavras-chave: Amazonas. Mito. Christine de Pizan. Boccaccio. Reescrita.

* Doutora em Letras pela Universidade Federal de Pernambuco (2006), professora do Departamento de Letras Clássicas e Vernáculas da UFPB. Áreas principais de pesquisa: Literatura Medieval, Gênero, Literatura Francesa, Literatura africana de expressáo francesa, Literatura Brasileira, Tradução literária, Literatura Popular

Esta obra está licenciada sob uma Licença Creative Commons. 
Re-vision - the act of looking back, of seeing with fresh eyes, of entering an old text from a new critical direction - is for woman more than a chapter in cultural history: it is an act of survival. Until we understand the assumptions in which we are drenched we cannot know ourselves. And this drive to self-knowledge, for women, is more than a search for identity: it is part of our refusal of the self-destructiveness of male-dominated society. (RICH, 1979, p.35) ${ }^{2}$

Quase quatrocentos anos antes da inglesa Mary Wollstonecraft publicar um dos primeiros clássicos da literatura feminista, $A$ Vindication of the Rights of Woman (Uma reivindicação dos direitos da mulher), Christine de Pizan (1364-1430) escreveu, em 1405, sua obraprima La Cité des Dames ( $A$ Cidade das Damas), livro que parece anunciar a reflexão da poetisa feminista Adienne Rich, transcrita acima, acerca da importância de revisitar o passado para entender o presente e planejar o futuro. Considerada a primeira obra a questionar a supremacia masculina em relação à mulher em vários domínios, $A$ Cidade das Damas busca reavaliar o papel feminino ao longo dos tempos, através da compilação de exemplos de várias figuras históricas, lendárias, mitológicas, de grandes virtudes, que deram prova da capacidade intelectual e física, cujas histórias foram emprestadas de obras de escritores de renome, como Ovídio, Virgílio, Jean de Meung, Jehan Le Fèvre, Boccaccio.

Entre esses escritores citados por Christine de Pizan, Boccaccio aparece com bastante ocorrência, o que nos levou a analisar, neste ensaio, o diálogo entre as biografias femininas propostas pela autora em $A$ Cidade das Damas, e aquelas escritas por Giovanni Boccaccio (1313-1375) em De Claris Mulieribus, focalizando nas duas obras a representação do mito das Amazonas. Antes de procedermos ao trabalho analítico entre

\footnotetext{
${ }^{2}$ Re-visão - o ato de olhar para trás, de enxergar com outros olhos, de penetrar em um texto antigo através de uma nova direção crítica - é para a mulher mais do que um capítulo na história cultural: é um ato de sobrevivência. Até que entendamos os pressupostos em que estamos submersas não poderemos conhecer a nós mesmas. E esta via de autoconhecimento, é para as mulheres mais do que uma busca de identidade: é parte de nossa recusa da auto-destruição da sociedade machista [traduçáo nossa]
} 
as perpectivas dos dois autores italianos, proponho revisitar brevemente aspectos importantes da bio/grafia dessa escritora medieval.

\section{Christine de Pizan e os primeiros passos do discurso feminista}

A desconstrução da "ordem do discurso" patriarcal, reconfigurando a imagem da mulher presente na literatura do final da Idade Média, corresponde ao projeto político-literário da escritora Christine de Pizan, que através de seu testemunho tornou-se uma das principais pioneiras na genealogia feminista. Para Eliane Viennot (2004, p.47),

Pela primeira vez foi enunciada uma verdade a qual falsos raciocínios e zombarias durante séculos tentaram ocultar: a cultura, e não a natureza, é o que se está na origem da inferioridade das mulheres. Pela primeira vez, uma mulher ousou contestar a supremacia dos intelectuais baseando-se no que eles julgam ser de sua competência: a argumentação, a história; empregando aquilo de que as mulheres são acusadas de serem desprovidas: a razão ${ }^{3}$.

Nos capítulos sobre História do primeiro volume do Segundo sexo, a feminista Simone de Beauvoir também alude ao pioneirismo da autora:

É nessa época que se inicia a Querelle du roman de la Rose. Pela primeira vez, vê-se uma mulher pegar da pena para defender seu sexo; Christine de Pisan ataca vivamente os clérigos em Épître au Dieu d'amour. Alguns clérigos, imediatamente, se levantam para defender Jean de Meung; mas Gerson, guarda-selos da universidade de Paris, apoia Christine, redige, em francês, seu tratado a

\footnotetext{
${ }^{3}$ Pour la première fois a été énoncée une vérité que des siècles de faux raisonnements et de gauloiseries avaient tenté d'occulter : c'est la coutume, et non la nature, qui est à l'origine de l'infériorité des femmes. Pour la première fois, une femme a osé contester la suprématie des intellectuels en se situant sur ce qu'ils estiment leur terrain : l'argumentation, l'histoire; en usant de ce dont ils disent les femmes dépourvues : la raison.
} 
fim de alcançar um público mais amplo. Martin le Franc joga no campo de batalho seu indigesto Chaperon des Dames que ainda é lido duzentos anos depois. E Christine intervém de novo. Reclama principalmente que se permita às mulheres instruírem-se: "se fosse costume pôr as meninas na escola e normalmente se lhes ensinassem as ciências como o fazem com os meninos, elas aprenderiam tão perfeitamente e entenderiam as sutilezas de todas as artes e ciências como eles entendem". (BEAUVOIR, 1970, p.132)

O poema narrativo Épître au Dieu d'amour, mencionado por Beauvoir, corresponde a uma das principais obras de Pizan e foi escrito em 1399, na charneira de sua trajetória literária, momento desencadeador da célebre batalha de cunho político-social em forma de debate literário, conhecida como "Querelle des femmes". O objeto central da "Querelle", presente nas obras citadas por Beauvoir, consistia na valoração positiva ou negativa da natureza feminina e da participação social das mulheres ao longo dos séculos. A "Querelle" se estendeu até o século XVIII e contou com a participação de vários outros escritores e escritoras que, buscando responder a obras de teor misógino com argumentos a favor do "segundo sexo", contribuíram para a construção de um combate em defesa da deshierarquização entre os sexos e da emancipação feminina.

Dentre as escritoras pioneiras, destacamos: Marguerite de Navarre, no século XVI. Sua obra Heptaméron (1540-1549) denuncia as várias formas de violência que caracterizam a sociedade renascentista e a ideologia do discurso filosófico que lhes serve de alicerce. No início do século XVII, vale ressaltar os escritos de Marguerite de Valois, Discours sur l'excellence des femmes ou Discours docte et subtil dicté promptement par la reine Marguerite (1614) e de Marie de Gournay, De l'égalité des hommes et des fermmes et Le Grief des dames (1626), que, discutem a problemática da mulher intelectual face à misoginia dos discursos oficiais da época. No final desse século, a inglesa Mary Astell aponta para a importância da educação das mulheres em A Serious Proposal to the Ladies, for the Advancement of Their True and Greatest Interest (1694). No século das 
Luzes, a romancista Riccoboni de Lambert, autora de Histoire de miss Jenny (1764) e Histoire d'Ernestine (1765)", cujas personagens femininas são levadas pelo desejo de escapar à tutela masculina (BROUARDARENDS, 2004, p.79), tem seus méritos de escritora reconhecidos pelos enciclopedistas Diderot e Choderlos. No final do século XVIII, dois importantes escritos marcaram os primeiros passos da luta da emancipação feminina: a Déclaration des droits de la femme et de la citoyenne (1791), da escritora e militante francesa Olympe de Gouges, guilhotinada em 1793, e a publicação em 1792 de $A$ Vindication of the Rigths os woman, da escritora britânica Mary Wollstonecraft.

Porém, se, como essas, várias outras escritoras, a partir da Querelle des femme, mantiveram continuamente sua participação no processo de elaboração e desenvolvimento de grandes debates políticos e intelectuais do momento, tiveram que resistir a vários obstáculos, percorrendo um caminho muito mais longo e espinhoso do que aquele percorrido pelos homens. As portas fechadas das universidades, a concepção reinante de uma «natural» inferioridade intelectual, os preconceitos morais da profissionalização feminina e todas as estratégias possíveis de torná-las excluídas do saber e da construção política e mental da sociedade, são testemunhos, de um lado, da dificuldade enfrentada pelas mulheres do saber, e de outro, da impossibilidade de nulificar o saber feminino, ao tentar condenar suas ideias ao esquecimento. A ascensão referente à participação feminina no universo da intelectualidade, seja enquanto mulheres eruditas, místicas, teólogas, poetas, romancistas, doutas, filósofas, confirma um surpreendente poder de resistência e de várias vitórias nas querelas de gênero, travadas ao longo dos séculos, ora no campo literário, ora no jurídico, ora no domínio da sexualidade, mas, sempre em busca, ao mesmo tempo, da igualdade entre os sexos e do direito à diferença. Eis a essência do paradigma das relaçóes sociais entre os sexos, uma das chave das questôes de gênero.

As vitoriosas "intelectuais", tendo a pena como instrumento, e mostrando um interesse específico sobre a questão feminina de cada época, transformaram o debate puramente literário em uma discussão política, iniciado, como vimos, com a desconstrução da teoria aristotélica 
da "polaridade dos sexos", no final da Idade Média, através da Querelle des femmes.

A entrada de Christine de Pizan no "Campo das Letras" se deu como meio de sobrevivência e de alívio moral face à morte de seu marido. Viúva, aos vinte e cinco anos, com três filhos para sustentar, além de sua mãe, também viúva e uma sobrinha. Da morte do marido à publicação de Epistola ao Deus do Amor se passaram dez anos, em que pesavam em sua produção poética o tom melancólico, memorialista e com o foco na sua condição de viuvez. Para a viúva no período medieval pareciam restar-lhe dois caminhos: a vida religiosa ou um outro casamento. Caminhos rejeitados pela escritora Christine de Pizan, que preferiu a dedicação à sua atividade literária e a defesa das mulheres como objetivo de vida, escolhendo uma vida independente e sozinha, como expressam os primeiros versos de sua mais célebre balada:

"Seulete suy et seulete vueil estre,

Seulete m'a mon doulz ami laissiee, Seulete suy, sanz compaignon ne maistre, Seulete suy, dolente et courrouciee (...)

\author{
"Sozinha sou e sozinha quero estar, \\ Sozinha deixou-me meu doce amigo, \\ Sozinha sou, sem companheiro nem mestre, \\ Sozinha sou, queixosa e exasperada. (...)”
}

A imagem melancólica, à qual Pizan frequentemente foi associada, a julgar pelos seus poucos e únicos versos editados nos manuais e antologias de Literatura Medieval, até pouco tempo, foi se redefinindo nos últimos anos do século XX com o crescente impacto das publicaçôes de traduçôes para o francês moderno, e para outras línguas, de obras da escritora.

A Cidade das Damas e Epistola ao Deus do Amor fazem parte do conjunto de sua vasta obra, composta de uma variedade de gêneros e modalidades literárias: baladas, virelai, rondós, lais, epístolas, tratados morais, biografia, etc. Em muitos de seus escritos, Pizan insere elementos autobiográficos, até mesmo na biografia do rei Charles V, encomendada pelo irmão do rei, duque Philippe de Bourgogn. Ao narrar a biografia do rei, dados autobiográficos se entrecruzam em algumas passagens, como 120 
a que ela narra seu deslocamento da Itália até a França, aos quatro anos, juntamente com a famíla, a pedido de Charles V, que acolheu no Palácio do Louvre, o célebre astrólogo de Bolonha, Thomas de Pizan, pai da escritora e sua família. Dentre as características do rei destacadas na sua biografia, está a sabedoria e o gosto pelo saber intelectual. Na sua morte, em 1380, havia cerca de 917 volumes, entre os quais toda a obra de Aristóteles traduzida em latim. Cruzar sua trajetória de vida com a do rei "Sábio" sugere um duplo propósito: de um lado, dar credibilidade ao seu testemulho biográfico, de outro, mostrar a fonte de sua erudição, e se autoafirmar como mulher escritora, em meio a uma forte onda misógina que abalava a literatura da época. Como temáticas recorrentes em suas obras apontamos ainda os princípios da ordem de cavalaria e a valorização da força física e moral, como o Livre des Fais d'armes et de chevalerie, e Livre du Corps de Police, como também, temas que a revelam grande pacificadora: Lamentation sur la guerre civile, Livre de la paix, Epistre de la Prison de vie humaine, Epistre à la Reine. Porém, a questáo feminina é visivelmente o tema central de suas obras, mais especificamente em Livre des trois vertues, Epître au Dieu d'Amour, Ditié sur Jeahne D'Arc e $A$ Cidade das Damas. Dessa última, passaremos a tratar nas linhas que seguem.

\section{Cidade das Damas: a construçáo de uma ginecotopia como refúgio contra os ataques misóginos}

A cidade imaginária de Christine de Pizan trata de temas como educação, igualdade e diferença entre os sexos, estupro, e introduz um tema novo no século XV: a importância de um espaço próprio para abrigar o processo da escrita, o "quarto só seu" de que nos fala Virgínia Woolf (1929), cinco séculos mais tarde, em $A$ room of one's own. Com muita recorrência, seu "quarto de estudo" aparece em evidência nos seus 
escritos e nas belas iluminuras que ilustram seus manuscritos, como a inserida a seguir:

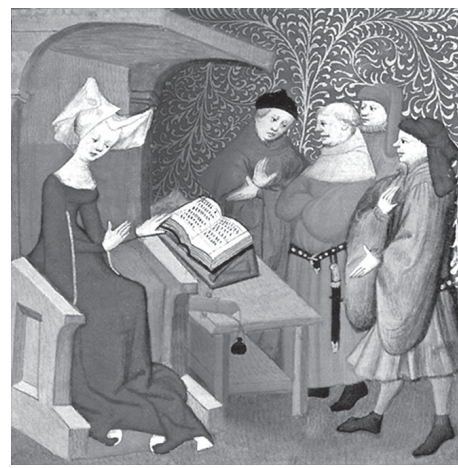

Christine de Pizan Writing in her Study

(miniatura do manuscrito de Harley MS. 4431, fol. 4-British Library)

O quarto de estudo é o espaço de referência no relato inicial da obra A Cidade das Damas, quando a voz da personagem narradora Christine revela o sentido da construçáo de uma cidade para as mulheres. Em um momento de semi-adormecer, depois de se mostrar cansada após um dia de muito estudo, a personagem Christine, de cabeça baixa, protegida pelas mãos, percebe um raio de luz que desce ao seu colo, trazendo-lhe à sua frente três virtudes personificadas em Dama Razão, Dama Retidão e Dama Justiça, que a ajudarão a construir uma cidade-fortaleza para proteger as mulheres das acusaçóes caluniadoras presentes em grande parte nos escritos da época. $\mathrm{O}$ raio de luz, que desce em direção ao colo da personagem, configura-se como uma metáfora que reflete o desejo de fertilidade de tais virtudes, pois uma vez acolhidas no colo feminino, reproduziram-se em vários outros exemplos de virtude feminina.

$A$ Cidade das Damas é dividida em três partes e cada uma corresponde ao diálogo da personagem narradora Christine com uma das três alegorias referidas: Razão, Retidão e Justiça, respectivamente. $\mathrm{Na}$ primeira parte, a Dama Razão ergue a base da Cidade imaginária, com exemplos de mulheres guerreiras e sábias. A inteligência e a força são as características em evidência nesse primeiro "Livro". Na segunda parte o 
diálogo entre Christine e Retidão coloca o acento nas virtudes morais como a fidelidade, lealdade, compaixão, senso de justiça, humildade, generosidade, através de histórias de esposas, filhas, mães, rainhas, que deram provas de bravura e ética ao longo da história. Na terceira parte, trata-se do povoamento da obra já construída. Dama Justiça inicia convidando a Virgem Maria, em seguida narra várias histórias de Santas, e finaliza estendendo o convite às mulheres de todas as classes sociais para se protegerem dos ataques misóginos de homens de má-fé, abrigando-se na Cidade das Damas, construídas para elas. Vejamos um pequeno trecho do último capítulo:

Que Deus seja louvado, minhas veneráveis Damas! Pois, nossa cidade está aqui construída e perfeita, na qual, com grande honra, todas vocês, que amam a glória, a virtude e a notoriedade, poderão hospedar-se; pois ela foi fundada e construída para todas as mulheres honradas - as do passado, do presente e as do futuro. [...] Enfim, todas vós, senhoras, damas de grande, média e humilde condição, antes de qualquer coisa, tende cuidado e sede vigilantes para vos defender contra os inimigos de vossa honra e de vossa virtude. Vede, minhas damas, como de toda parte esses homens vos acusam dos piores defeitos! (PIZAN, 2012, p. 338)

O catálogo de histórias de mulheres virtuosas que compóem a Cidade das Damas foi inspirado em grande parte na obra do seu compatriota Boccaccio, autor renomado de De Claris Mulieribus e de Decameron. Muitos exemplos da primeira obra do humanista italiano foram reescritos por Christine de Pizan, com uma nova roupagem. Três pontos essenciais nas propostas iniciais dos dois autores encontram-se na origem da distinção das suas obras: a motivação de seus escritos, a escolha das virtudes merecedoras de classificar certas mulheres como ilustres e a perspectiva de gênero que marca as histórias narradas.

Se, para Pizan a defesa das mulheres contra a misoginia dos literatos e filósofos do passado e de seu presente está na origem de sua motivação para construir a alegórica "Cidade das Damas", a proposta de 
Boccaccio é de outra ordem, como ele próprio expõe no prólogo de $D e$ Claris Mulieribus (2010, p. 60):

E se os homens são dignos de serem louvados por terem realizado grandes façanhas pela força que receberam, quanto não serão as mulheres, as quais são dotadas pela natureza (quase todas) de um corpo frágil, debilitado, e de uma mente sórdida, quando se atrevem a realizar empreitadas de grandes dificuldades, inclusive para os homens, com um ânimo viril, gênio brilhante e uma virtude notável?

Por essa razão, para não retirar-lhes seu mérito, ocorreume, para a glória de sua grandeza, desenvolver em um livro a história das que me vierem à memória. E acrescentar, entre muitas outras, aquelas que fizeram notáveis a audácia, o vigor de seu gênio, a atividade, os dons da natureza ou as graças ou desgraças do destino. $[\ldots]^{4}$

Se, para Pizan, os exemplos de mulheres valiosas são buscados para desconstruir a suposta superioridade masculina em relação à natureza feminina, na obra de Boccaccio, a inferioridade das mulheres em relação aos homens é uma ideia recorrente, o que o levou a mostrar com admiração aquelas que trasncederam essa inferioridade, demonstrando qualidades e habilidades alheias à sua natureza, como os exemplos dos seus comentários, mostrados por Días-Collarejo (2010, p.16), na introdução da edição espanhola Mujeres preclaras:

\footnotetext{
4 "Y si los hombres son dignos de alabanza por llevar a cabo grandes hazañas con la fuerza que se les dio, ¿̨cuánto más no lo serán las mujeres, a las que la naturaleza dotó (a casi todas) de un cuerpo blando y débil y de una mente torpe, cuando se atreven a realizar empresas que serían muy difíciles incluso para los hombre, con un ánimo viril, un ingenio brillante y una notable virtud?

Por esta razón, para no restarles su mérito, se me ocurrió para gloria de su grandeza, desarrolar en un libro la historia de las que me vinieran a la memoria. Y ańadir, entre otras muchas, a aquéllas a las que hicieron notables la audacia, el vigor de su ingenio, la actividad, los dones de la naturalza o las gracias o las desgracias de la fortuna.[...]" As citaçōes da obra de Boccaccio foram retiradas da tradução espanhola de Violeta DíazCorralejo, intitulada Mujeres preclaras, com tradução nossa para o português.
} 
Eva foi "movida pela leviandade feminina[...] e pensou estupidamente..” (I, 6). Em compensação, Semíramis "desmintindo seu sexo, realizou muitas obras grandes e ilustres" (II, 6). Ísis "o que é mais notável em uma mulher, aguzado o gênio como se fosse um homem, ensinou..." (VIII, 4). Artemisa "com força viril, [...] demonstrou seu grande valor (LVII, 10) e ainda provou que a natureza às vezes se equivoca, pois no seu caso "quem podemos pensar se náo é por um erro da natureza criadora lhe foi dado o sexo feminino ao corpo que Deus infundio uma magnífica alma varonil?” (LVII, 21)

Quanto à escolha das mulheres ilustres, a personagem Dama Justiça, no último capítulo da Cidade das Damas, citado acima, esclarece que o critério do povoamento dessa cidade alegórica não é apenas uma questão biológica, mas de valor, pois não basta pertencerem ao sexo feminino, mas é necessário serem mulheres honradas. Por sua vez, Boccaccio esclarece que o emprego do termo "fama" não corresponde ao sentido restrito, que sempre alude à virtude, mas sim, em um sentido mais amplo de "considerar famosas as que por qualquer façanha ficaram conhecidas no mundo todo" (idem, p. 60). Outro esclarecimento que encontramos no prólogo de De Claris Mulieribus é que não serão contempladas histórias de mulheres santas, cujos méritos já foram ilustrados nos livros sagrados. O objetivo de Boccaccio é de apresentar os méritos das mulheres pagãs, nunca publicados em volume algum, e lhe pareceu também que "não devia misturar com estas, quase todas pagãs, as da história sagrada, as judias ou as cristãs, pois não parece que se adequem bastante nem que se apresentem no mesmo nível." ${ }^{6}(i d e m$, p. 61).

\footnotetext{
${ }^{5}$ Eva fue "movida de su ligereza femenina [..] y pensó estúpidamente..." (I, 6). En cambio, Semíramis "desmintiendo su sexo, llevó a cabo muchas obras grandes e ilustres" (II, 6). Ísis "lo que es más notable en una mujer, aguzado el ingenio como si fuera un hombre, enseńó..." (VIII, 4). Artemisa "con fuerza viril, [...] demostró su mucha valía (LVII, 10) y además probó que la naturaleza a veces se equivoca, pues en su caso "¿qué podemos pensar sino que por un error de la naturaleza creadora al cuerpo, al que Dios infundió una magnífica alma varonil, le fue dado el sexo feminino?" (LVII, 21).

6 "no debía mezclar con éstas, casi todas paganas, a las de la historia sagrada, las hebreas o las cristianas, pues no parece que se adecuen bastante ni se presenten en el mismo nivel.
} 
A fim de examinarmos o terceiro item de divergência que apontamos entre os dois projetos literários, propomos a análise da representação do mito das Amazonas, nas obras de Boccaccio e de Pizan.

\section{As Amazonas nas representaçóes de Boccaccio e de Christine de Pizan}

Representadas desde a Antiguidade, em textos enciclopédicos e gravuras antigas, as Amazonas ora evocam imagens de mulheres intrépidas, ora imagens de crueldade e transgressão da natureza. No final da Idade Média, em particular, depois da obra boccacciana De Claris mulieribus, o mito das guerreiras ressurge em vários países da Europa, seja na Literatura, tapisseria, gravuras, estátuas, iluminuras, etc. (VIENNOT, 2008, STEINER, 1999).

Figuras de Amazonas aparecem entre outras heroínas no tema literário conhecido por "Les Neuf Preuses" ("As nove Bravas" ou "As nove da Fama"), como o equivalente feminino do célebre leitmotif da literatura cortês francesa, "Les neuf Preux", que aparece na obra Les Voeux du Paon, de Jacques de Longuyon, em 1312-1313 (CERQUIGLINI-TOULET, 1993 , p. 35-44). Esse tema literário foi também reproduzido em outros países da Europa, sob a denominação de "Nove Prodi", em italiano, "Nine Worths", em inglês, "Nove da Fama", em português. Trata-se de heróis históricos ou legendários de renome, divididos em três grupos, sendo três reis pagãos, três hebreus e três critãos: Josué, David, Judas Macabeu, Alexandre Magno, Heitor, Júlio César, rei Artur, Carlosmagno, Godofredo de Bulhão. O tema das "Neuf Preuses" que aparece no final do mesmo século, na obra Le Livre des Lëesce, de Jehan Le Fèvre, foi inspirado nas guerreiras pagâs da Antiguidade, sendo quatro rainhas "Bravas": Semiramis, Tamaris, Teuca, Deifile e cinco rainhas Amazonas: Hipólita, Sinope, Lampeto, Menalipe, Pentesileia. Outras versôes das Nova da Fama foram adaptadas, a partir do século XV, também em três tríades: pagãs, judias e cristâs, com variantes entre as versôes. $\mathrm{Na}$ tradiçấo germânica, por exemplo, encontramos as judias Débora, Judith, 
Esther, uma tríade pagã com Lucrécia, Vetúria e Virgínia, e as cristãs santa Helena, santa Brigite e santa Elizabeth.

Christine de Pizan na Cidade das Damas reproduz a divisão em tríade, incorporando, contrariamente à obra de Boccaccio, as mulheres judias e cristâs na lista de mulheres bravas. Destacaremos a seguir a representação das Amazonas que são mencionadas nas duas obras, apontando as marcas ideológicas na construção discursiva de cada autor.

A personagem Razão, na obra de Pizan, narra em quatro capítulos aspectos do reinado das Amazonas, contextualizando-o e evidenciando a atuação das principais guerreiras. O primeiro capítulo se intitula, "Amazonas", o segundo "Sobre Tomíris, rainha das Amazonas", o terceiro, "Como o grande Hércules e seu amigo Teseu chegaram da Grécia para atacar as Amazonas por terra e por mar, e como as senhoritas Menalipe e Hipólita os desarmaram, fazendo cair cavalos e cavaleiros, o último capítulo trata da "Rainha Pentesiléia e da ajuda que ela levou à cidade de Tróia”.

Primeiramente, interessa-nos identificar a reescrita do mito tradicional sobre o reino das Amazonas. As histórias sobre as Amazonas vêm logo em seguida do capítulo sobre a guerreira Semirámis, escolhida para ser a primeira pedra a ser colocada na construçâo da Cidade das Damas, como explica a Dama alegórica Razão:

Bela e cara amiga, agora que te preparei as grandes e profundas escavaçôes, cavando toda a terra e carregando-a sobre meus próprios ombros, é hora de assentar as grandes e fortes pedras dos alicerces para construir as muralhas da Cidade das Damas. Pegue, então, a pá de tua pluma e prerara-te para construir e lavorar com grande empenho. Aqui, está uma grande pedra que gostaria que fosse a primeira a ser assentada na fundação da tua Cidade. Pode-se ver, nos signos astrais, que Natureza a predestinou a ser colocada e incorporada a esta obra. Afasta-te um pouco e eu colocarei para ti esta primeira pedra. (PIZAN, 2012, p. 99) 
É emblemático, como podemos perceber, o lugar de relevância que ocupa as Amazonas na obra de Pizan, como fundação da fortaleza. Os primeiros exemplos de mulheres encontrados na Cidade das Damas poderiam ser compreendidos, naquele momento histórico, como contraexemplos de características e papéis sociais atribuídos ao sexo feminino: a força, a coragem, as atividades de guerra, etc

No entanto, tais características são apontadas de maneira positiva na obra, em que se justifica a necessidade de certos atos, podendo ser considerados de violência e, ao mesmo tempo, acrescentam-se ao perfil de guerreiras traços de mulheres amorosas, sentimentais, como ilustra o trecho sobre a origem dessa ginecotopia:

[...] Um dia, os efeitos devastadores da guerra terminaram privando aquela cidade de todos os homens nobres que ali viviam. As mulheres do país, vendo que todas haviam perdido seus maridos, irmãos e pais, e só restavam os velhos e as crianças, reuniram-se, corajosamente, para decidir o que fazer. No final, deliberaram que, daquele momento em diante, elas iriam governar o reino sem tutela masculina[...].Todavia, para assegurar uma descendência, elas iriam a países vizinhos, em determinadas épocas do ano, voltando, em seguida, ao seu país: se dessem luz a crianças do sexo masculino, elas reenviariam aos seus pais, e se, ao contrário, fossem do sexo feminino, cuidariam de sua educaçáo.[...] (PIZAN, 2012, p.102)

Em De claris mulieribus, o relato sobre o nascimento dos filhos das Amazonas é outro:

[...] se uniam aos vizinhos para conseguir descendência e quando concebiam regressavam rapidamente à sua terra. Matavam no ato os que nasciam varóes e educavam com cuidado as mulheres para milícia[... $]^{7}(2010$, p.94)

\footnotetext{
${ }^{7}[$...] se unían a los vecinos para conseguir descendencia y en cuandto concebían regresaban rápidamente a su tierra. Mataban en el acto a los que nacían varoen y educaban con cuidado a las mujeres para la milicia, [...].
} 
Outros pontos de divergências nesse capítulo das duas narrativas merecem ser destacados. Primeiramente, a valorização que é dada à história de Lampedo e Marpásia. Observa-se que em $\mathrm{CM}^{8}$, apesar das duas rainhas das Amazonas darem título ao capítulo (numerado XIXII), suas histórias são relegadas ao segundo plano. A ênfase é dada ao surgimento do reino das Amazonas e a história dos reis Sylisios e Scolopicus concorrem em ordem de importância com a das irmãs Marpásia e Lampedo, que, segundo Boccaccio, se autoproclamaram rainhas das Amazonas. Contrariamente na $\mathrm{CD}^{9}$, no capítulo XVI sobre "As Amazonas", Christine de Pizan trata da origem deste reino governado por mulheres guerreiras, acentuando os feitos gloriosos das irmãs citadas que teriam sido coroadas rainhas pelas outras Amazonas por serem "duas de suas mais nobres damas"(p.102). A menção à morte da rainha Marpásia, que encerra o capítulo, é outro ponto revelador da divergência dos pontos de vista entre as duas narrativas. $\mathrm{Na}$ versão boccacciana, a morte de Marpásia - "que, aliás, se deu por ela acreditar demasiadamente em si mesma" - representa por extensão a derrota das Amazonas, uma vez que desse ataque de inimigos poucas guerreiras sobreviveram. A voz narrativa finaliza afirmando que náo se recorda de ter lido algo sobre o que aconteceu com Lampedona. $\mathrm{Na} \mathrm{CD}$, a personagem Razáo relança a narrativa após o episódio da morte, preferindo náo encerrar o capítulo com uma derrota, mas com as vitórias de Sinoppe, a guerreira que dá continuidade ao projeto das Amazonas: “[...] Então, no seu lugar, as Amazonas coroaram uma de suas filhas, virgem, nobre e bela, que se chamava Sinoppe.[...]Vingou a morte de sua mãe de maneira exemplar[...] e conquistou, ainda, muitos outros países.".

Nos capítulos seguintes, são preservadas as mesmas estratégias pelos autores: $\mathrm{Na} C D$, a reflexão sobre a capacidade de resistência das Amazonas e da durabilidade de seu reinado, que abre e/ou fecha cada capítulo, funciona como segmento estruturador da narrativa de Pizan, formando uma história dentro da "História das mulheres", contada na obra de Pizan. O procedimento de reiteraçáo de certos elementos

\footnotetext{
${ }^{8}$ A partir de agora passaremos a designar De Claris Mulieribus por CM

${ }^{9}$ A partir de agora passaremos a designar A Cidade das Damas por CD.
} 
valorativos das rainhas Amazonas se define, assim, como a representação do eterno retorno de mulheres ilustres ao longo da História.

Em CM, os segmentos conclusivos aludem, ao contrário, às derrotas das Amazonas, e ao caráter negativo e anti-natural das guerreiras. As diferenças de ponto de vista podem ser melhor percebidas no quadro comparativo a seguir, cujo enfoque se concentra no desfecho de cada capítulo: ${ }^{1011}$

\begin{tabular}{|c|l|}
\hline Capítulos & \multicolumn{1}{|c|}{ De Claris Mulieribus } \\
\hline XI-XII & $\begin{array}{l}\text { "Marpásia, confiando demasiadamente em si } \\
\text { mesma, foi morta com parte das tropas[..." } \\
\text { "Não me lembro de ter lido sobre o que aconteceu } \\
\text { com Lampedona"11 }\end{array}$ \\
\hline XIX-XX & $\begin{array}{l}\text { Quando Oritia soube que Teseu, aliado de Hércules } \\
\text { na expedição, havia levado Hipólita, buscou reforços } \\
\text { e decidiu declarar guerra a toda Grécia, mas, esses } \\
\text { mesmos reforços a abandonaram, por causa de } \\
\text { dissençóes entre eles. Os atenienses venceram-na, } \\
\text { ela regressou a seu reino, e não me lembro o que } \\
\text { conseguiu realizar depois. }\end{array}$ \\
\hline XXXII & $\begin{array}{l}\text { Há quem admirem as mulheres que, armadas, se } \\
\text { atrevemalutar com homens, mas a admiraçáo diminue } \\
\text { se pensarmos que o hábito muda a natureza fazendo } \\
\text { Pentisileia e as que são como ela se transformarem } \\
\text { pelo uso das armas e serem mais homens do que } \\
\text { aqueles que a natureza fez de sexo masculino e que por } \\
\text { ociosidade e moleza se transformaram em mulheres } \\
\text { ou em lebres com casco. }{ }^{13}\end{array}$ \\
\hline
\end{tabular}

\footnotetext{
${ }^{10}$ No recuerdo haber leído lo que fue luego de Lampedona. (p. 95)

${ }^{11}$ Cuando Oritia supo que Teseo, aliado de Hércules en la expedición, se había llevado a Hipólita, buscó refuerzos y decidió declarar la guerra a toda Grecia, pero, esos mismos refuerzos la abandonaron, a causa de las disensiones entre ellos, los atenienses la vencieron, regresó a su reino y no recuerdo qué logró realizar después. (p. 118).

${ }^{12}$ Hay quienes admiran a las mujeres que, armadas, se atreven a luchar con hombres pero la admiración disminuye si pensamos que ele hábito cambia la naturaleza por lo que 


\begin{tabular}{|c|l|}
\hline Capítulos & \multicolumn{1}{|c|}{ Cidade das Damas } \\
\hline XVI & $\begin{array}{l}\text { Dessas duas rainhas, a primeira a morrer foi } \\
\text { Marpásia, em uma batalha. Então, no seu lugar, } \\
\text { as Amazonas coroaram uma de suas filhas, virgem } \\
\text { nobre e bela, que se chamava Sinoppe. Ela era } \\
\text { táo orgulhosa e corajosa que nunca quis unir-se a } \\
\text { nenhum homem, ficando virgem toda sua vida. E } \\
\text { não teve outro amor nem prazer além das armas. } \\
\text { Vingou a morte de sua máe de maneira exemplar: } \\
\text { todos os habitantes do país, onde sua mãe foi } \\
\text { morta, foram levados ao fio de espada e suas terras } \\
\text { devastadas; e conquistou, ainda, muitos outros } \\
\text { países. (p.103) }\end{array}$ \\
\hline XVII & $\begin{array}{l}\text { Bela cara amiga, lembro-te essas coisas porque } \\
\text { diz respeito ao tema do qual estou te falando, } \\
\text { mesmo se conheces táo bem, visto que tu } \\
\text { mesma já havias citado, há algum tempo, em } \\
\text { teu Livre de la mutacion de Fortune, assim } \\
\text { como em Epistre de Othea. Agora, te darei mais } \\
\text { exemplos. (p. 105) }\end{array}$ \\
\hline XVIII & $\begin{array}{l}\text { Hércules tanto pediu e rogou à rainha, que } \\
\text { obteve dela a mão de Hipólita apara Teseu e a } \\
\text { permissão para conduzi-la ao seu país. Depois } \\
\text { das bodas matrimoniais, partiram os gregos. E, } \\
\text { assim, Teseu levou consigo Hipólita, com quem } \\
\text { teve, depois, um filho, chamado Hipólito, que } \\
\text { foi um cavaleiro de muito valor e grande renome. } \\
\text { E quando, na Grécia, souberam que estavam } \\
\text { em paz com as Amazonas, grande foi a alegria, }\end{array}$ \\
\hline temerdade, não havia nada que eles \\
\hline
\end{tabular}

Pentesilea y las que son como ella se convierten por el uso de las armas y son más hombres que los que la naturaleza hizo machos por el sexo y que por la ociosidaaad y la molicie se convierten en mujeres o en liebres con casco. (p. 156) 


\begin{tabular}{|l|l|}
\hline XIX & $\begin{array}{l}\text { Como podes escutar, foi assim que foi fundado e } \\
\text { se manteve o reino das mulheres, de grande poder, } \\
\text { que durou mais oitocentos anos; podes verificar tu } \\
\text { mesma, nos livros de história, o tempo compreendido } \\
\text { entre a fundação até depois da conquista de } \\
\text { Alexandrre Magno, que conquistou o mundo na } \\
\text { época. A história nos conta como Alexandre chegou } \\
\text { a seu reino e foi recebido pela rainha e sua corte. Esse } \\
\text { Alexandre viveu bem depois da fundação de Roma, } \\
\text { que é bem posterior a essa destruiçáo. E se queres } \\
\text { brincar de confrontar as várias crônicas e calcular o } \\
\text { número de anos, perceberás que esse reinado teve } \\
\text { duraçáo imensa. Entre os reinos conhecidos com tal } \\
\text { duração, não encontraremos príncipes mais nobres } \\
\text { e numerosos, nem que tenham realizado atos mais } \\
\text { gloriosos, do que foram e fizeram as damas e as } \\
\text { rainhas daquele reino. (p. 113) }\end{array}$ \\
\hline
\end{tabular}

A partir da visão dos dois quadros, chama-nos atenção a divergência de extensão dos parágrafos conclusivos dos capítulos em análise. A concisão e os "esquecimentos" manifestos nos desfechos das narrativas de Boccaccio sugerem, senão uma desvalorização da importância das guerreiras Amazonas, um recurso ideológico que proclama os princípios morais da sua época. Neste sentido, a obra $\mathrm{CM}$ vai de encontro com os valores misóginos do final da Idade Média, bem como reproduz a visão de mundo dos textos Antigos grecolatinos e suas releituras em obras medievais que lhe serviram de inspiração.

Christine de Pizan, ao contrário, após a narração de cada história, prolonga-se em detalhes e comentários positivos sobre as guerreiras, reiterando seus feitos heróicos e concluindo sempre com uma situação favorável às Amazonas. Descrito de maneira hiperbólica, o reino das Amazonas é comparado a outros reinados masculinos, realçando sua durabilidade e resistência. Outra estratégia retórica empregada pela escritora é o recurso à autocitação. $\mathrm{O}$ cuidado em fazer referências às 
fontes bibliográficas das suas narrativas mitológicas e históricas aponta para duas estratégias: comprovar a veracidade das histórias mencionadas na obra, atestando a fonte de seu conhecimento, bem como incluir-se dentre a bibliografia pesquisada, atribuindo a si própria uma autoridade. $\mathrm{O}$ recurso à autocitaçáo lhe garante assim um reconhecimento autoral entre as demais obras de autoria masculina, contribuindo para uma maior divulgação de suas obras, e marcando também uma atitude de superioridade em relação a Boccaccio. Enquanto a voz narrativa de CM confessa sua falta de lembranças em relação a mais detalhes sobre as histórias narradas, dama Razão em CM apresenta uma narrativa muito mais completa, com riquezas de detalhes, já sendo conhecidos e citados pela própria Christine, em outras obras.

\section{Consideraçóes finais}

A partir deste breve estudo comparativo entre as representaçóes do mito das Amazonas nas obras De Claris Mulieribus e A Cidade das Damas, é notória a ressiginificação feminina do mito na obra de Christine de Pizan. Neste sentido, compreendemos melhor a importância da leitura de obras como essa de Pizan, distante mais de seis séculos de nossa era, mas de algum modo táo atual. Basta lembrar que a reeleitura da Literatura canônica assim como a ressignificação de figuras femininas da Mitologia e da História se constituem em um dos debates centrais da crítica e da teoria feministas atuais, desde a reivindicação de Um teto todo seu (1929), de Virgínia Woolf, o questionamento do patriarcado em O Segundo Sexo (1949), de Simone de Beauvoir, até os ensaios das teóricas do feminismo dos anos 60, 70, 80 como Kate Millet, Elaine Showalter, Adrienne Rich, Susan Gubar, Sandra Gilbert, Joan Scott.

Concordando com Rita Schmidt (2006, p. 107),

a desconstrução do mito através de sua ressignificação em termos do campo de percepção das relaçóes entre as mulheres 
é parte dessa operação cognitiva que a voz feminina, de forma consciente e deliberada, busca articular para, nesse processo, construir uma subjetividade como espaço discursivo, lugar onde outros conhecimentos sáo forjados.

A busca por esse espaço significante na História constitui um dos desafios da literatura escrita por mulheres como meio de libertação dos mitos sobre o feminino reproduzidos nas sociedades patriarcais. A questáo da autoria continua, ainda no nosso século, uma contenda das mulheres-escritoras, bem como de outros grupos excluídos do cânone, na busca para se construir uma outra verdade, livre das estruturas de poder e dominação características da Literatura hegemônica. Segundo Oberti (2000, p. 03),

O patriarcado, ou como queiramos denominar ao sistema de dominação, não é um sistema fechado [...], mas sim formas hegemônicas de poder - masculino que revelam suas próprias falhas [...] a tarefa estratégica do feminismo é explorar essas brechas onde houver e também ajudar a produzi-las.|

[Texto recebido em maio de 2013 para compor a corrente edição especial]

\section{Referências}

BEAUVOIR, Simone. O segundo sexo. Trad. Sérgio Millet. 4.ed. São Paulo: Ediçẫo Européia do Livro, 1970.

BOCCACCIO, Giovanni. Mujeres preclaras. Tradução e apresentação de Violeta Díaz-Corralejo. Madri: Cátedra letras Universales, 2010. BROUARD-ARENDS, Isabelle. De l'auteur à l'auteure. In: RACINE, $\mathrm{N}$; TEBITSCH, M. (Org.) Intellectuelles: du genre en histoire des intellectuels. Bruxelle : Editions compexes, 2004. 
CERQUICLINI-TOULET, Jacqueline. " Fama et les preux: nom et renom à la fin du Moyen Âge ", Médiévales, 24, 1993, p. 35-44.

OBERTI, Alejandra. O labirinto da diversidade. Folha Feminista, n. 15. São Paulo: SOF, p. 01-03, 2000.

PIZAN, Chrisitne. A Cidade das Damas. Tradução e apresentação de Luciana Eleonora de Freitas Calado. Florianópolis: Editora Mulheres, 2012.

RICH, Adrienne. On Lies, Secrets, And Silence: Selected Prose 19661978. New York: W. W. Norton \& Company, 1980.

STEINER, Sylvie. Le mythe des Amazones et son utilisation politique de la Renaissance à la Fronde. In : WILSON-CHEVALIER, Kathleen ;

VIENNOT, Éliane. (Org.). Royaume de Fémynie. Pouvoirs, contraintes, espaces de liberté des fermmes, de la Renaissance à la Fronde. Actes du Colloque international de Blois des 12-14 octobre 1995 organisé par l'American University of Paris. Paris: Champion, 1999, pp. 261-273

VIENNOT, Éliane. Les Amazones dans le débat sur la participation des femmes au pouvoir à la Renaissance. In : LEDUC, Guyonne (Org.). Réalité et représentations des Amazones. Paris: L'Harmattan, 2008.

VIENNOT, Éliane. Les intellectuelles de la Renaissance : enjeux et conflits d'une émergence. In: RACINE, N; TEBITSCH, M. (Org.) Intellectuelles: du genre en histoire des intellectuels. Bruxelle: Editions compexes, 2004, pp.43-46.

WOOLF, Virginia. A Room of One's Own. London \& New York: Harcourt, 1989.

The rewriting of the myth of the Amazons in The City of Ladies by Christine de Pizan

Abstract: This article aims to analyze the reappropriation of the myth of the Amazons by writer Christine de Pizan (1364-1430), in The Book of City 
of Ladies (1405), identifying in her writing the features of feminist thought. For the comparative analysis, it will be proposed a dialogue between the female biographies presented in The Book of City of Ladies, and those presented by the Italian writer Boccaccio (1313-1375), De Claris Mulieribus, focusing the representation of the myth of the Amazons on theses two works.

Keywords: Amazons. Myth. Christine de Pizan. Boccaccio. Rewriting

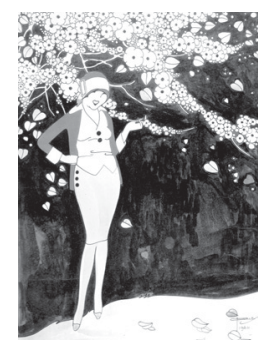

